\title{
Is Attending a Mental Process? ${ }^{1}$
}

[This is the penultimate draft; final version forthcoming in Mind \& Language]

Abstract The nature of attention has been the topic of a lively research programme in psychology for over a century. But there is widespread agreement that none of the theories on offer manage to fully capture the nature of attention. Recently, philosophers have become interested in the debate again after a prolonged period of neglect. This paper contributes to the project of explaining the nature of attention. It starts off by critically examining Christopher Mole's prominent "adverbial" account of attention, which traces the failure of extant psychological theories to their assumption that attending is a kind of process. It then defends an alternative, process-based view of the metaphysics of attention, on which attention is understood as an activity and not, as psychologists seem to implicitly assume, an accomplishment. The entrenched distinction between accomplishments and activities is shown to shed new light on the metaphysics of attention. It also provides a novel diagnosis of the empirical state of play.

\section{INTRODUCTION}

Investigating the nature of attention has been a central task for cognitive psychology for over a century. Much more recently, the topic has started to attract interest again from philosophers, after a prolonged period of neglect. Philosophy may have a part to play, in view of how the research programme in psychology appears to have stalled in recent decades. Various different theories have been proposed over the years, claiming to identify the mechanism that constitutes attention. But the suspicion has become fairly widespread that none of the theories on offer actually manages to produce a fully adequate account of the nature of attention. In a famous survey article, Alan Allport expresses a sentiment, widely shared more than two decades after its publication, of disillusionment with the project:

[E]ven a brief survey of the heterogeneity and functional separability of different components of ... attentional control prompts the conclusion that, qua causal mechanism, there can be no such thing as attention. There is no one uniform computational function, or mental operation (in general, no one causal mechanism), to which all so-called attentional phenomena can be attributed. (1993: 203).

Before resigning to the sort of skepticism Allport is driven to, however, it is worth exploring whether a different range of conceptual tools, not available to psychology, might help clear the waters. This is precisely what the recently revived philosophical inquiry into the nature of attention hopes to

\footnotetext{
${ }_{1}^{1}$ I'm very grateful for extremely useful comments on earlier drafts from Maria Alvarez, David Hillel-Ruben, Noa Leibowitz, Conor McHugh, James Stazicker, Marius Usher, Daniel Whiting, and audiences at Southampton University, and the 2016 conference of the European Society for Philosophy and Psychology in St. Andrews.
} 
achieve, an inquiry which this paper aims to advance. If the psychological project of explaining the nature of attention repeatedly comes up empty-handed, this might be because the wrong questions have been asked or the wrong assumptions made.

The present paper endorses a position along these lines. It claims to expose and correct a mistaken underlying picture of the metaphysics of attention which arguably drives the psychological project to its inevitable failure. The guiding question prompting this diagnosis is the titular one. But the mistake diagnosed here is not that of answering 'yes' where the correct answer is 'no'. The latter is a striking position defended by Christopher Mole (2011a; 2011b). According to Mole's attentional adverbialism, the psychological research programme goes wrong in assuming that to explain the nature of attention is to identify the kind of process instantiated by episodes of attending. The present paper closely examines, and ultimately rejects, Mole's case for denying that attention is a mental process, in favour of a more subtle alternative. Attention is in fact a process; but not the kind of process psychologists have been (implicitly) assuming. Once the operative notion of process is properly understood, a more enriched metaphysical scheme emerges with an appropriate place for the type of process instantiated by attending. It is conjectured that the psychologists' mistake lies in (implicitly) treating attention as an accomplishment, where in fact it is an activity. The distinction between accomplishments and activities is spelled out below, with several distinguishing marks noted. Introducing this distinction into the debate over the metaphysics of attention sheds new light on the phenomenon. Besides the doubt it casts over attentional adverbialism, it also suggests an alternative diagnosis of the state of deadlock the psychological programme finds itself in, and points to alternative directions for investigating the nature of attention.

The next section (2) sets out Mole's adverbialist view, according to which attention designates a mode or manner of $V$-ing, viz. $V$-ing attentively, rather than an independent mental process of paying attention. Section 3 argues against this view. It suggests that attention is not plausibly understood along adverbialist lines (\$3.2). Before that, the section also critically examines Mole’s arguments against the process-based view of attention (\$3.1). Section 4 then advances an alternative metaphysics of attention. The distinction between processes qua activities and processes qua accomplishments is set out, and it is shown that attention belongs in the former category ( $\$ 4.1)$. It is then conjectured that psychologists may have mistakenly assumed it belongs in the latter (\$4.2). 


\section{ADVERBIALISM ABOUT ATTENTION}

In a rich and stimulating work, Christopher Mole (2011a) develops a novel theory of the nature of attending, according to which attention is 'cognitive unison'. Roughly, Mole's theory states that one is attending to some task $t$ iff all of one's available cognitive resources are devoted to executing $t$. However, the focus in what follows will be on assessing not this constructive position but rather its underlying critical drive. For Mole's contribution consists as much in his attempt to reorient the contemporary debate over the nature of attention as in the detail of the particular proposal he favours.

Mole's view offers an alternative to extant philosophical and cognitive-psychological explanations of attention, first and foremost in virtue of the distinctive form his explanation takes. He surveys some of the main theories of attention that have been proposed over the years with an eye to exposing the source of their continued failure to adequately explain what attention is. According to Mole, that failure can be traced to a common underlying assumption about the metaphysical category attention belongs to. The lively research programme starting with James' Principles of Psychology (1890) onwards operates under the misguided assumption that to explain the nature of attention is to identify the type of mental process that token episodes of attention instantiate. And it is largely due to this (typically implicit, unargued for) assumption that extant theories of attention predictably continue to fall prey to counterexamples.

To illustrate Mole's critical outlook, consider briefly the theory of attention as "feature integration" or "feature binding". A task of identifying a combination of two or more properties requires that one pay attention. For example, when asked to spot red triangles in a crowded visual field that contains both nonred triangles and non-triangle red shapes, one's attention is claimed to consist in binding together the various independently registered properties of objects, so as to build an integrated 'object file' (Treisman and Gelade 1980; Triesman 1998). But it is not hard to see that the feature integration paradigm is at best incomplete as a general theory of attending. Brief reflection brings to mind counterexamples to the necessity of feature-binding to attention. One may, for example, attend to an object that does not display multiple properties which could be integrated. Similarly, even if the object in question does have multiple features that could be bound together, one's aim or purpose in attending to it (e.g. selecting a color to paint one's 
house) may require only that one of its features be attended to (viz., its color). In such cases, there is attention without feature-binding.

Other candidate-theories illustrate a similar problem of limited application. Consider the theory of attending as the filtering of information for further processing. The key idea here is that perceptual processing faces capacity limitations resulting in informational 'bottlenecks', with attention required to filter the information which will be processed or be processed consciously (Lavie \& Tsal 1994). Counterexamples to this hypothesis as a general account of attention come from scenarios in which capacity limitations are not operative, e.g. when only one stimulus is available for processing. Or again, consider the different 'spotlight' theory of attention which, unlike the filtering theory, does not emphasize the question of which object will be selected for processing but rather where the object is located. On this theory, attention operates like a spotlight that moves around and focuses on a specific region where the attended object is located. However, there are clearly cases where attention is not allocated on the basis of spatial location - for example, turning one's auditory attention to a sound while not being able (or interested) to determine its location. For similar reasons, the spotlight theory is ill-suited to handle attention in thought (e.g. attending to a puzzle in order to solve it).

Examples like the above quickly illustrate an emerging pattern which casts doubt over the prospect that any specific cognitive process will manage to explain the nature of attention (Section 4.2 contains a more elaborate discussion of extant psychological paradigms of attention). For any such process can seemingly be transposed to a context in which its original function - feature-integration, filtering, task switching, or whatever - loses its point, since the object attended to or the nature of the task do not require the operation of the mechanism in question. This troubled dialectic prompts some to adopt a pessimistic stance on the project of seeking a theoretically unified understanding of attention, as expressed by Allport in the passage quoted above. Mole shares Allport's view of the contemporary research programme on the nature of attention. But importantly, he goes on to propose that its poor track record is a predictable symptom of a deeper structural flaw.

The flaw lies in the implicit structural assumption already noted, whereby an explanation of attention should proceed by identifying the kind of process attention consists in. According to Mole, attending is an adverbial phenomenon; 'attention' does not designate any one kind of process taking place, but rather a 
possible way or manner or mode for something - anything - to be taking place. When one is paying attention, one is performing some act $(V)$ attentively. And there is no process taking place over and above $V$ itself which could possibly constitute one's attention. Consequently, no process-based explanation of attention could ever succeed. Instead, an adequate explanation should focus on specifying what is involved in the attentive mode or manner of $V$-ing. To illustrate, consider one of Mole's analogies, viz. employment (2011a: 12-3). If we are after an explanation of the nature of employment, we would be looking in the wrong place in seeking to identify what is going on in observed instances of employment. For one's $V$-ing will count as an instance of employment for virtually any value of $V$, provided the circumstances are apposite - that one is contracted to $V$, is providing some professional service by $V$-ing, and so on. The right way to explain employment is evidently a matter of explicating the correct circumstances under which one's $V$-ing counts as employment.

For another of Mole's illustrations, contrast combustion with baste (2011a: 25-6). An explanation of the former is plausibly process-based; it involves identifying and explicating the process combustion consists in, viz. burning. But an explanation of haste, in contrast, would be adverbial: virtually anything could be done hastily, provided it is done in the correct way, i.e. hastily, which typically involves doing it with rapidity, rashness, and so on. According to Mole's process-eliminativism about attention, attending is relevantly similar to employment and haste, and relevantly dissimilar to combustion. This is a striking thesis with dramatic implications for our (empirical and metaphysical) understanding of attention. Mole goes on to articulate and defend the particular adverbial account of attention he favours which, as briefly noted above, turns on the idea that $V$-ing attentively is $V$-ing with cognitive unison. But rather than engage with Mole's constructive proposal, the next section takes a closer look at his process-eliminativism. For it is unclear that its strong conclusion is in fact warranted.

\section{AGAINST ATTENTIONAL ADVERBIALISM}

On a thin, innocuous sense of the term, 'adverbialism' about attention is undeniable: there is a manner of $V$-ing, namely $V$-ing attentively, which may apply to virtually any substitution for ' $V$ '. However, as we have seen, the relevant sense of 'adverbialism' here is much more radical, and is akin to 
the original use in the philosophy of perception, from which Mole borrows the label. Adverbialism about perceptual experience seeks to expunge what it regards as the ontologically dubious notion of sense-data: when one perceives a red object, one does not stand in a relation to some mysterious mental entity, viz. a 'sense datum'. Rather, one simply perceives in a particular mode or manner, viz. 'red-ly'. ${ }^{2}$ Adverbialism about perceptual experience does away with the idea of a mental object of perception. And similarly, adverbialism about attention does away with the idea of a mental process of attention.

The present section makes a two-pronged case against Mole’s adverbialism. The argument of $\$ 3.2$ suggests that the view fails to capture certain forms of attention. Before then, $\$ 3.1$ shows that Mole's purported counterexamples to the process-based view are unsuccessful. The counterexamples in question are designed to illustrate the insufficiency of any particular process to one's attending. More precisely, they are designed to illustrate the supervenience-failure of attention on mental processes. A defense of the process-based view of attention, as attempted in this paper, would therefore do well to consider such cases.

\subsection{Supervenience failure?}

As Mole points out, process-based theories are committed to the supervenience of attention on mental processes. If attention does not supervene on mental processes, then a fortior it does not consist in mental processes, as the process-based view maintains. And crucially, according to Mole, this supervenience thesis indeed fails. For we can take two scenarios across which all mental processes are fixed but the circumstances vary, and we shall find that in the first case one is attending, but in the second one is not (2011a: 36-41).

To illustrate, take the feature-binding theory again. If one is engaged in a task that requires binding together different features of an object, a process of feature-binding may plausibly constitute one's attention. But the same process of binding may fail to constitute one's attention when transposed to a different scenario, e.g. where one is wholly occupied with some single train of thought. In the latter scenario, one's 'bound experience of that object may be nothing more than a slight distraction from

${ }^{2}$ Aune (1967: 147-8); Chisholm (1957: 115-125). 
[one's] thinking' (38). Here, binding the features constitutes distraction, not attention, and hence supervenience fails. For another of Mole's illustrations of supervenience-failure, consider the attentiondemanding task of quickly coming up with random sequences of numbers (Baddeley 1966). Being occupied with this task, one's attention seems to consist in switching between different strategies for generating random sequences so as to avoid non-random patterns from emerging, as will tend naturally to happen. But in a different scenario where one is occupied by a single line of thought, switching between randomization strategies is again distracting and hence constitutes 'failures of attention, not instances of it' (2011a: 39). Mole realizes of course that two examples do not amount to a decisive refutation of the process-based approach. But he contends that their similar structure suggests a recipe for generating further objections to other variants of the process approach.

In fact, however, the examples do not illustrate damaging supervenience-failure at all, for the simple reason that distraction can itself constitute attention. In the original scenario of each pair, one's attention is focused on a task involving feature-binding or strategy-switching. When transposed to the second scenario, one's attention starts by being focused on a single train of thought, and then shifts (partly or wholly) to some secondary object, viz. the source of distraction - a feature-bound object or complex taskswitching. At most, this shows that changing the circumstances while holding mental processes fixed may change the object of one's attention. The upshot may be supervenience-failure of attending-to-object-O on mental processes; the upshot will not be supervenience-failure of attending as such on mental processes. And the latter is all the process-based approach is committed to. To be sure, Mole's counterexamples do demonstrate that neither feature-binding nor strategy-switching are necessary for attention. This may suggest that task-switching and feature-binding are processes of the wrong order of specificity to constitute attention (more on this below). The point, however, is that none of this impugns the very idea that attention consists in some kind of mental process. Holding all processes fixed in Mole's scenarios does seem to ensure that attention is being paid - whether in the form of feature-binding, task-switching, or the pursuit of a single train of thought.

Mole considers a reply to his counterexamples that builds on a similar point to the one just made. The reply he imagines avoids his objection by proposing a (presumably long) disjunction of processes as what attention consists in: Attention is either feature-binding, or task switching, or ... But Mole protests 
that the resulting list would be gerrymandered and hence risks trivializing the process-based view (2011a: 40). Now Mole's rejection of a disjunctive version of the process-based view is compelling as far as it goes. However, it does not vindicate his counterexamples, since the process-based view need not maintain that attention consists in some disjunction of the sort he imagines. Instead, the view can and should propose that attention consists in some process that is less specific or specialized than task-switching, feature-binding and the like. Some other, broader kind of process may stand to all such specific instances as a genus to its species. For example, in a review of Mole's work, Watzl (2011) proposes that a personallevel process, or alternatively some holistic sub-personal process along biased-competition lines may be precisely of the right order of specificity to avoid the threat of triviality. ${ }^{3}$

A second reply Mole considers opts for a composite rather than disjunctive process-based metaphysics. Attention is never exhausted by task-switching or feature-binding etc., but rather consists in some complex combination of such processes; hence it is no surprise that some 'pure' instances of taskswitching and feature-binding fail to constitute attention. Mole seems to think that this response presents an over-complicated picture of what is often enough a rather simple phenomenon, e.g. the paying of attention by binding together the features of some object. But once again, the process-based view may identify a single, yet suitably general, kind of process as what constitutes attention (compare Watzl, 2011). And such a process may be as simple as any other. Whether or not such a general process can be identified remains open for debate. But absent an argument to the effect that it cannot, Mole fails to refute the process-based approach.

\subsection{Intrinsically attentional deeds}

The previous subsection was concerned with rebutting Mole's argument against the process-based view. This serves to weaken the overall case for his favored adverbalist alternative; but it does not attack adverbialism directly. That is the main order of business here.

Consider driving attentively, which involves such things as listening to oncoming traffic, or looking out for pedestrians, or calling to mind the meaning of the road sign ahead, or trying to work out which

\footnotetext{
${ }^{3}$ I am grateful to an anonymous referee for bringing Watzl's discussion to my attention.
} 
exit leads to one's destination, or.$^{4}$ Attentional adverbialism denies that these are independent processes. Rather, listening to the traffic, looking out for pedestrians, and so on are taken to occur as part of one's (token) act of driving; they constitute attending to one's driving when and because they instantiate the attentive manner of one's (token) driving. More generally, then, attentional adverbialism minimally requires a schema with two elements: a token act $V^{\text {tkn }}$, and a list of processes $\left\{\mathrm{M}_{\mathrm{i}}, \ldots, \mathrm{M}_{\mathrm{n}}\right\}$ that constitute one's attending in virtue of instantiating the attentive manner $M$ of one's $\mathrm{V}^{\mathrm{tkn}}$-ing. It will now be argued that this schema fails, and consequently so does attentional adverbialism. There are cases where one is paying attention but there are no plausible substitutions for $V$ such that one's attending could be constituted by an attentive modification of one's $V$-ing. This is because, to anticipate, some acts necessarily involve attention and so cannot be performed either attentively or inattentively, as adverbilaism requires. The possibility - indeed, the ubiquity - of such intrinsically attentional deeds belies the adverbiliast schema which turns on teasing apart the act from its contingent attentive manner.

The point can be demonstrated with the aid of a distinction drawn by Alan White (1964: 8-17) between two different types of attending, viz. attending as an agent and attending as a spectator. Under the former type, one is necessarily the agent of the action one is attending to. This type of attention is most naturally described as attending to what one is doing where this is equivalent to doing that thing attentively. Under the latter type, in contrast, one need not be the agent of what one is attending to. Thus a novice may attend as a spectator to her own driving, which would typically be done in order to correct any mistakes and learn the right moves; but equally she could attend in this sense to her instructor's driving, in which case she could not be attending to what she is doing.

Agential attention seems to fit comfortably with the adverbial schema: one is engaged in an act of driving $\left(\mathrm{V}^{\mathrm{tkn}}\right)$, and attending to one's driving is constituted by the above processes (listening to oncoming traffic etc.), if and when they occur, in virtue of their instantiating the attentive manner of one's driving. But consider a case of spectator attention, e.g. the novice attending to her instructor's driving. What are the appropriate substitutions for $V$ and $\left\{\mathrm{M}_{\mathrm{i}}, \ldots, \mathrm{M}_{\mathrm{n}}\right\}$ here? Notice fist that the novice need be engaging in nothing over and above observing the instructor, and yet may still be paying attention. That only a single

\footnotetext{
${ }^{4}$ Of course, no single such occurrence is entailed by one's driving attentively. But if no such occurrence is taking place, then one must be driving inattentively. This is important for what follows.
} 
activity - viz., observing - is taking place makes it hard to see how the adverbialist could come up with two independent elements to plug into the two variables in her schema. Clearly, she cannot plausibly suggest that that $\mathrm{V}^{\mathrm{tkn}}=\left\{\mathrm{M}_{\mathrm{i}}, \ldots, \mathrm{M}_{\mathrm{n}}\right\}=$ observing the instructor. For there would then be no difference between preforming the act attentively and performing it inattentively.

The difficulty for the adverbialist here arises because observing (and likewise listening, looking, concentrating, and so on) are intrinsically attentional deeds: they entail attention in some form or other, to at least some degree. To say of someone that they are observing inattentively is to say that they are not observing carefully, i.e. failing to pay full (or serious, or sufficient) attention; it is not to say that they are failing to attend at all. Conversely, to say that one is observing attentively is to say that one is observing carefully or with extra attention, not that they are observing with something, viz. attention, that would be wholly absent had their observing been performed inattentively. It is hard to make sense of the idea that one could observe without paying any attention at all. ${ }^{5}$ The intrinsically attentional nature of observing and the like undercuts a different tack the adverbialist may attempt, viz. to understand $V$ as one's observing the instructor's movements, and $\left\{\mathrm{M}_{\mathrm{i}}, \ldots, \mathrm{M}_{\mathrm{n}}\right\}$ as the processes involved in one's observing the movements attentively, whatever these processes happen to be exactly. This tack fails since, again, observing as such entails attending, which would imply, paradoxically, that attention is being paid not just when the attentive manner is instantiated but when the inattentive manner is instantiated, too.

Mole himself denies that the distinction between 'agent' and 'spectator' marks two kinds or forms of attention. On his view, the two are distinguished by involving different cognitive tasks attended to: learning how to drive in the case of the spectator vs. driving (as well as perhaps learning) in the case of the agent (Mole 2011a: 73-4). This suggests a way of filling out the above schema by substituting 'learning how to drive' for $V$, and the specific processes involved in attentively learning how to drive, whatever these turn out to be, for $\left\{\mathrm{M}_{\mathrm{i}}, \ldots, \mathrm{M}_{\mathrm{n}}\right\}$. However, the suggestion may at best handle cases where one's observing

\footnotetext{
${ }^{5}$ Mole may wish to deny that observing (listening, looking, etc.) inattentively necessarily involves attention to at least some degree (cf. Mole 2011a: 53). This is because, as noted briefly above, Mole's constructive adverbial theory of attention centers on the idea that attention is cognitive unison: an agent attends to what she is doing just in case none of the cognitive resources that could potentially serve the task she is performing are occupied with something that does not in fact serve it. The view seems to imply the denial of partial or graded attention: if one's cognitive resources are not wholly occupied by the task at hand, one is not attending (Mole 2011a: 83-5. And see Wu 2014: 102-3 for discussion). This is not the place to assess the prospects of Mole's theory of attention as cognitive unison. But the implausibility of denying the notion of partial or divided attention would seem to impugn his substantive theory as well as its adverbialist foundations, as explained in the text.
} 
is embedded in or serves a broader, non-intrinsically-attentional task such as learning how to drive. But, as already pointed out, observing may occur independently of any such task. Further, one's observing may be part of another intrinsically attentional task, which similarly tells against the present suggestion. Consider for instance observing one's surroundings in order to be immersed in the beautiful scenery, or thinking about an equation in order to solve it, or simply observing $O$ for its own sake. In all such cases, the present proposal would once again struggle to single out an act or task $V$ that is performed attentively only in some circumstances.

Finally, might the adverbailist manage to decompose observing itself into a non-intrinsically-attetnional component and an attention-instantiating manner? A seemingly promising candidate for the former is one's seeing. However, there is a serious problem with this proposal, which stems from the fact that 'seeing' designates a state, not any kind of process (act or event). ${ }^{6}$ This runs counter to the adverbial schema adumbrated above, where 'attentively' was taken to modify some act or event $V$. Even setting aside the oddity of such expressions as 'seeing attentively', it is just hard to see how an adverbial modification of a state like seeing could ever amount to the dynamic act of paying attention.

No proof has been offered that the substitutions for $V$ and $\left\{\mathrm{M}_{\mathrm{i}}, \ldots, \mathrm{M}_{\mathrm{n}}\right\}$ considered and rejected above are exhaustive of the theoretical options available to the adverbialist. But the most plausible candidates, including one inspired by Mole's own remarks, have been surveyed and found wanting. They include all the natural descriptions of what one is up to when attending as a spectator. This warrants the conclusion that adverbialism tries but fails to undermine the process-based view. The alternative metaphysics it proposes in its place cannot capture spectator attention which involves intrinsically attentional deeds and (sometimes) nothing besides. And furthermore, as argued in the previous subsection, Mole's argument against the process-based approach misses its mark. Plausible versions of the approach are not vulnerable to his purported counterexamples. If there is a flaw in extant paradigms, then,

\footnotetext{
${ }^{6}$ The next section will set out various contrasting logico-linguistic features of different types of process, in the course of arguing that attending is an activity. But to verify quickly here that seeing belongs in a separate category of statives, distinct from all processes, notice that (a) Like all stative verb-phrases, and unlike processes, 'seeing' does not take imperfective aspect (cf. the deviant 'he was seeing the bird take flight'); and (b) Seeing, like all states, lasts for a time, whereas processes take time or go on for a time. Much more on this in section 4 below.
} 
it seems to lie elsewhere than its process-based metaphysics. The next section attempts to pinpoint where exactly.

\section{ATTENTION AS ACTIVITY}

\subsection{Process, accomplishment, activity}

Some incomplete accounts of attention have been briefly rehearsed in $\$ 2$ above. It has been argued that Mole goes too far in diagnosing their failure to deliver a fully general account as due to a misclassification of attention in the logical category of process. But a somewhat different diagnosis than Mole's may yet support a less radical verdict. If the mistake of extant theories lies not in deploying $a$ mental process to explain attention, perhaps it lies in deploying the wrong kind of process. The conjecture explored in this section is that attention can be understood as a mental process, but only one characterized at a higher level of abstraction than that of feature-binding, task-switching, and the like.

This hypothesis actually seems to gain support from one source of inspiration for Mole's adverbialism, viz. Alan White (White 1964; see Mole 2011a: 48-50, 119-120). Some of White's remarks clearly do seem in line with Mole's own position. For example, White characterizes attention as a 'polymorphous activity-concept', which implies 'many different activities, the engagement in one or other of which can in certain circumstances count as [attending], and yet none of which activities in other circumstances necessarily counts as [attending]' (1964: 5-6). White's examples of polymorphous activities include practicing and repeating, which belong in the same logical category of adverbials as Mole's example of employment: they are all phenomena explicable purely by the relational, never the intrinsic, properties of one's deed. That attention should be grouped together with employment (and practice and repetition) as an adverbial phenomenon is a claim disputed above; to that extent, the approach developed in this paper likewise resists thinking of attention as a 'polymorphous activity' in White's sense. Nevertheless, some of White's other remarks seem in fact to suggest a different line than Mole's. He writes:

Because we focus on what is perceptible by using the appropriate sense-faculty and on what is intelligible by making it the object of our thinking, we can specify the general notion of attention in terms of these particular perceptual and intellectual activities ... When we speak of attention being 
paid or given, drawn or attracted, it is basically some set of these perceptual and intellectual activities to which we refer (1964: 8).

This remark seems to endorse the idea of attention as a mental (perceptual or intellectual) process. On this way of reading White, what he is primarily concerned to resist is an explanation of attention as an overly specific process:

To give one's attention to one's philosophy involves reading books, doing essays, going to lectures, and in other ways spending time on the subject ... yet each of these activities might be done in circumstances such that philosophy ... was not their centre; they would not then count as paying attention to one's philosopby [1964: 7; emphases added].

This remark could be read as saying that a change in circumstances may lead to a change in the object of attention without a change in whether attention is being paid (a point echoed in $\$ 3.1$ above when discussing Mole's counterexamples). One may be attending to the lecture so as to discern the origin of the speaker's accent rather than her penetrating philosophical insights; similarly, reading a philosophy book may be done with the aim of finding misprints rather than inspiration. That attention is being paid does not tell us to what, or what for, it is being paid. This will be important for what follows.

The primary aim here is not exegetical. It therefore matters little whether the above is in fact the correct way to read White. The substantive picture developed here is one on which, contrary Mole, attending can and should be thought of as a mental process, but one characterized at a suitable level of abstraction. As stated, the point is obscure. To throw it into sharper focus, we must tease apart two logically distinct notions that might be lumped together under the general term 'process', viz. - activity and accomplishment.

The publication of Zeno Vendler's "Verbs and Times" (1957) launched a tradition that has since become canonical, of drawing distinctions between different verb-types (Vendler's discussion systematizes some distinctions drawn previously by Ryle [1949: ch. 5]). Using Vendler's classic scheme, the central distinction for present purposes is that between activities (e.g. run around, push a cart, swim along, walk), and accomplishments (run-a-mile, build a house, paint a picture, eat an apple). (Two other 
categories - viz., achievements and states - are mentioned later on). The terminological labels for these categories tend to vary, but several distinguishing logical features are widely recognized (Kenny 1963, Mourelatos 1978, Galton 2007). One such salient group of features concerns how each verb-type relates to time. Activities, for example, occupy an essentially indefinite time stretch. Logically speaking, one can push a cart or run around indefinitely, since such activities involve no culmination point or anticipated result. Accomplishments, in contrast, are marked by an endpoint (the apple having been eaten, the mile having been run, etc.), and hence their duration corresponds to a definite stretch terminating at that point. Put differently, accomplishments take time, while activities go on for a time (Kenny 1963: 122-3).

Another time-related distinguishing feature is this. If $V$ is an accomplishment, we say that $\mathrm{A} V$-ed for the entire duration of $V$, not some part of it. Thus if Jones wrote a letter over the lunch break, she did not write the letter in the first fifteen minutes of the break. Relatedly, accomplishments are not 'homogenous': not every segment of one's writing a letter is itself a writing of a letter. Activities, in contrast, are homogenous: while Smith is pushing a cart, it is true that he is pushing it at each and every moment. Furthermore, with activities, if $\mathrm{A}$ is interrupted while $V$-ing (running), it is correct that $\mathrm{A}$ has $V$ ed (run). But if $V$ is an accomplishment, interrupting A's $V$-ing ensures that A has not $V$-ed.

The respective distinguishing marks just listed are importantly related to the telic nature of accomplishments and the a-telic nature of activities. Accomplishments, as already noted, are marked by having a terminus, a state that designates the successful completion of the occurrence in question. That is why, when an accomplishment is interrupted before being successfully completed, the perfective form 'A has $V$-ed' is inapplicable. It is likewise the reason why accomplishments take time; it takes time to complete them. But activities have no such endpoint or telos. They can therefore be continued indefinitely, and when interrupted they would still entail the perfective form. Other features that tell apart accomplishments from activities could be listed (e.g. accomplishments are amenable to countquantification while activities are amenable to mass-quantification; Mourelatos 1978: 427-8). But a detailed discussion of these features would constitute an unnecessary distraction from the main purpose here, which is to mark out the logical distinction between activities and accomplishments, and to note how they diverge on the fundamental feature of being telic or otherwise. 
The point can bear significantly on the question of attention as a mental process. Mole's use of 'process' in the course of denying that attention is a mental process is clearly meant to have very broad application; ${ }^{7}$ certainly his use is not sensitive to the activity/accomplishment distinction. Now we have seen in the previous section reasons to suspect that Mole's process-eliminativism is unwarranted. But once activities are properly distinguished from accomplishments, a less radical alternative hypothesis can be put forward: attending is not a mental accomplishment; it is, however, quite plausibly a mental activity.

The hypothesis gains support from the tests suggested by the Kenny-Vendler-Mourelatos scheme. Attending is a-telic. Very often one has an aim or purpose when attending to some object, such as understanding the elaborate point a speaker is conveying. That aim or purpose typically suggests what the achievement of one's attending would be, e.g. understanding (the speaker's point), noticing, realizing, or even hearing. Achievements such as these are thought by some (e.g. Vendler 1957; Ryle 1949: 131-4) to belong in a separate logical category; others group achievements together with accomplishments (Kenny 1963: ch. 8). ${ }^{8}$ But however achievements are classified, what is immediately relevant here is that they are not entailed by one's attending: one may listen but fail to notice anything at all. Here is U.T. Place (1954: 247):

\begin{abstract}
'Noticing' is an achievement concept like 'recognizing', 'perceiving', not an activity concept like 'pondering' or 'attending'. 'Noticing', 'perceiving' or 'recognizing' are the achievements that result from the activities of looking, listening, and attending. If one looks, listens or attends, one normally recognizes or notices something or other, but one can also attend and fail to notice; one can look and fail to see, listen and fail to hear.
\end{abstract}

No doubt there is also a further sense of 'noticing $O$ ' which is roughly equivalent to 'being aware of $O$, in contradistinction to noticing something about $O$, e.g. that $O$ is in fact an $F$. Of the two, only the latter constitutes an achievement; it is in this latter sense of 'noticing something about $O$ ' that the present discussion is concerned to deny that attending entails noticing. On the other hand, 'noticing' in the former sense of 'being aware of' is arguably (though controversially) entailed by attending. But in any

\footnotetext{
7 The closest Mole (2011a) comes to defining 'process' is on pp. 28-9: "The question of which processes happen is settled by the facts about what things happen to what ... 'What happens to what is a matter of the gaining and losing of properties by objects."

${ }^{8}$ A fourth category typically contrasted with achievements, activities, and accomplishments, is states (believing that dragons are real, being red all over). The latter last for a time, but do not take time or go on for a time. Linguistically, stative verb-phrases are marked by not taking imperfective aspect (cf. the deviant 'his shoes were fitting him').
} 
event, that sense of 'noticing' designates a (mental) state, and hence its entailment does not conflict with the point that attending is not, and does not entail, an achievement. (To verify that 'being aware of $O$ ' indeed designates a state, notice that, like all stative verb-phrases (see n. 5), it does not take imperfective aspect; hence the deviant-sounding 'he was being aware of the prowler's presence'.)

Moving on from a-telicity, we can note that no endpoint is implied by saying that one is attending. When one is listening to the crickets chirping, there is no endpoint such that if it is reached, one is no longer listening. To be sure, one cannot listen to the crickets chirping once they have stopped chirping. This demonstrates the fact that attention requires an object. ${ }^{9}$ But it does not imply that the nature of one's listening is defined by any endpoint such as the crickets stopping to chirp. Thus it remains the case that if one's listening is interrupted for whatever reason, it would be correct to say that one has listened to the crickets. ${ }^{10}$ This is in line with the above test for an occurrence being an activity rather than an accomplishment. Further, at every moment during the time at which one is listening, one can be correctly said to be listening; thus listening is homogenous, once again suggesting it should be thought of as an activity, not an accomplishment.

Further reflection will quickly verify that the other marks identified by the Kenny-VendlerMourelatos scheme classify attention in the category of activity. Thus, attention is subject to mass, not count, quantification. And since attending as such has no endpoint or terminus, it is logically indefinite. Attention is thus shown to be an activity, which itself is a species of process. This conclusion is hence at odds with Mole's process-eliminativism about attention. It also has instructive implications for the scientific inquiry into the nature of attention, as demonstrated in the next section.

An argument for treating attending as an activity can be found in Watzl (2017: ch. 3). (Watzl's book was unpublished at the time this paper was written.) There is no space here for the sort of lengthy discussion that would do justice to Watzl's complex position. But we can note that his aims in arguing that attending is an activity are very different from the present ones. Watzl aims chiefly to show how treating attending as an activity vindicates the thought that attention is subject to voluntary and

\footnotetext{
9 This seems at odds with thinking of vigilance as a genuine form of attention. For discussion, see Wu (2014: 93-5). 10 This is so even if the object of attention is, unlike chirping, itself an accomplishment, e.g. when one attends to a passerby eating her lunch. One's attending is constrained only by the continued existence of its object, even if the object itself it constrained by an endpoint.
} 
intentional control (see ch. 2 , sec. 5 especially), where the core notion of 'activity' is one on which '[v]ery roughly ... a subject engages in an activity when she is doing something' (50). For this purpose, it is primarily important for Watzl to tease apart activities in general, and the activity of attending in particular, from states. Later on (pp. 60 ff.), he distinguishes activities from accomplishments as well (using slightly different terminology) in the course of arguing that acts of attending are basic (i.e., not performed by first performing any other act). It should be clear that none of these claims are direct concerns of the present discussion.

\subsection{Lessons for the science of attention}

Several psychological theories of attention have been very quickly sketched above $(\$ 2)$, in the course of presenting Mole's diagnosis of their failure. That diagnosis has been rejected. But armed with the fresh understanding of attention as an activity, we can provide a more plausible one in its stead. An exhaustive survey of the scientific terrain would be out of place here, but citing a selective sample of the main theories should be enough to illustrate the central claim: For natural reasons, adumbrated below, the psychological research programme on attention tends to implicitly mistreat attending as an accomplishment or an achievement. This nicely explains why the programme has not been able to capture the nature of attention.

Start with some of the theories discussed by Mole. The theory of attending as feature binding, for example, was shown above to be extensionally inadequate (see also Quinlan 2003). Now if attending is indeed a mental activity, the failure of this theory is entirely unsurprising since feature binding or integration, at least on the present understanding of these locutions, is in fact an accomplishment. Creating a single unified object representation out of its different properties is the very endpoint or telos of the process of feature integration - a necessary property of accomplishments, necessarily absent from activities. Much the same applies to the theory of attention as a bottleneck or perceptual filter. Recall that on this paradigm, attention is thought of as a gateway of sorts that selectively allows only some stimulusrepresentations through, thereby determining which information will be available for processing. But conceptualizing attention in this way once again mistreats it as an accomplishment; the process of 
attending is marked by the endpoint of information passing through the bottleneck and exhibits all the essential features of accomplishments set out above.

Central to Broadbent's (1958) influential presentation of the filter theory was his idea of a 'capacitylimited system' that imposes processing limits, which in turn requires the operation of the attentional filter. And the same insight about capacity limits drives the rather different biased competition paradigm. Setting out from the idea that limited capacity makes it impossible to process all incoming stimuli, the thought here is that stimuli compete for resources and control. The competition is thought to be biased in favour of certain inputs compatible with the agent's goals, desires, emotions, etc. ('top-down' bias) as well as intrinsic features of the object's ('bottom-up' bias), such as its salience (Desimone \& Duncan 1995). Now the biased competition paradigm is vulnerable to counterexamples which expose it as insufficient for attending. Given that biased competition is a highly general and abstract idea, there are very plausibly many brain mechanisms that instantiate it (Duncan 2006) but have nothing to do with attending in particular. As Watzl recently put it, "Attention cannot be identified with biased competition processing, because many biased competition processes operate in the absence of attention" (Watzl, 2017: 31). Where the filter paradigm postulates a process marked by information passing through the attentional bottleneck, under the biased competition paradigm, the process corresponding to attention culminates in the competition being 'won' by one (informational) side. In both cases, the resulting processes are accomplishments rather than activities.

Both the filter and the biased competition paradigms stem from an entrenched theme in attention studies, going back as far as William James (1890), which views attention as essentially involving selection of objects or stimuli for processing. Selection is considered a hallmark of attention across different systems and different modalities. It may take place between different perceptual inputs or as a part of high-level cognitive operations, such as calling to mind some particular memory or choosing between alternatives in a decision problem (Chun et. al 2011: 75). Some even view selectivity as the defining feature of attention (Allport, 1987; Wu, 2011). However, once again, selecting is a paradigmatic achievement (if construed as the instantaneous effecting of choice) or an accomplishment (if construed more broadly to incorporate e.g. some of the cognitive process preceding the instant when choice is made); in any event, it is never an activity. Consequently, the proposal endorsed here would expect to find cases where the 
association between attention and selection breaks down. And indeed, while attending in typical environments often involves selecting inputs or objects, this is not necessarily so. Consider a case of (partial) sensory deprivation, where a subject is blindfolded, gagged, ear-muffed, and chained to a post in a cellar with no stimuli but a faint odor of eucalyptus in the air. When attending to the odor, there is no selection taking place, simply because there is only one stimulus present. (No doubt the subject can select whether or not to attend to the odor; but that is an act of choice or decision that preempts the paying of attention proper. $\left.{ }^{11}\right)$ The achievement/accomplishment of selecting thus also seems unable to capture the nature of attention - as the thesis of attention as activity predicts.

Finally, to conclude this brief survey, consider two related paradigms. The first has already been cited in $\$ 2$ above, along with counterexamples to its purported necessity for attention: it likens attention to a moving spotlight. Here again, the posited process - geared as it is towards some particular spatial region becoming the focus of cognitive processing - is an accomplishment. A related paradigm is that of signal enhancement, where attention is thought to facilitate better processing of the object or area to which attention is directed (Carrasco et. al. 2000). As one review states, "The signal enhancement hypothesis proposes that attention directly improves the quality of the stimulus representation by increasing the gain on the signal within the locus of attentional selection" (Carrasco 2011: 1489). Counterexamples to any suggestion that attending consists in signal enhancement are supplied, inter alia, by cases in which better performance is achieved in ways other than enhancement, e.g. by reducing external noise (Lu \& Dosher, 2000).

But does the present diagnosis apply? Can the fact that signal enhancement falls short of explaining the nature of attention be attributed to its failing to treat attending as an activity? It may seem doubtful that it can (as an anonymous referee helpfully pointed out). For on some possible interpretations of this locution, 'signal enhancement' seems actually to constitute an activity. We thus need to get clearer on what 'enhancement' actually means in the present context. Now two measures of enhancement or improvement in processing perceptual stimuli are accuracy and the ability to discriminate (Tootell et. al. 1998). However, response time is another central criterion of enhanced performance. But if enhanced

\footnotetext{
${ }^{11}$ But see Wu: (2014, pp. 81-2) for a dissenting view. There is no space here to consider Wu's position.
} 
processing of a stimuli is glossed (in part) as faster detection, then it does not designate an activity. For on this picture, attending is understood partly in terms of the achievement of detecting.

This last point may help to see why psychological theories end up employing a metaphysics of the wrong sort to provide a fully general theory of attending. The above survey confirms that extant paradigms are typically framed in terms of accomplishments or achievements. And in fact, this is entirely unsurprising given the methodology used in constructing the theories. Subjects in the experiments face cognitive tasks. Abstracting away from the particular experimental paradigm, a mechanism or process is identified, and claimed to be responsible for discharging the task. But the experimental tasks, and consequently the corresponding mechanisms, are geared towards a telos or endpoint. Subjects are prompted to attend to some object by being asked to detect it, identify it, recall it, and so on. The experimenter infers that the subject is attending by recording the achievements that attention typically results in, mentioned above: noticing, realizing, perceiving, and so on. It is hard to see what other methodology the experiments could employ. But the point remains that these achievements or accomplishments are not essential to the activity of attending. Consequently, while the psychological paradigms tell us a great deal about the modulatory effects of attention, they cannot hope to reveal the nature of attending.

This provides a more perspicuous understanding of the charge, leveled in a preliminary way above, that the paradigms are overly specific. They may capture those episodes of attending which do involve achievements, and moreover those specific achievements set by the experimental paradigm in question. But often enough one's attending will result in some other achievement or indeed, in no achievement at all. Any general account drawn from a limited class of instances is bound to over-generalize. There are grounds, then, for endorsing the conjecture that psychological theories have been operating with the mistaken assumption that attention is an accomplishment. In response, one could always claim that the present conjecture fails to diagnose the inability of extant theories to offer a fully general account of attention, simply because achieving this is not part of their aim. Put differently, perhaps the passage from Allport quoted in the Introduction above should be read not as a statement of disillusionment with the hunt for a general theory of attention, but rather as a dictum against embarking on such a hunt in the first place. Indeed, there is an increasingly stronger sentiment among theorists today that "[a]ttention is not 
unitary. Rather, attention should be considered as a property of multiple, different perceptual and cognitive operations" (Chun et. al., 2009: 76. See also Lavie et. al. 2004, Parasuraman 1998, and Pashler 1998).

Perhaps, then, the empirical research programme is not best thought of as failing to meet one of its stated objectives of explaining the nature of attention. But it is nevertheless highly instructive to learn its limitations: a fully general account of attention is unlikely, on principled grounds, to emerge from a research programme that treats attention as an accomplishment. That is one central benefit of acknowledging that attention is an activity. Moreover, beyond any implications for the science of psychology (and beyond its intrinsic theoretical value), construing attention as an activity casts doubt over attentional adverbialism, as shown in $\$ 3$, and can inform the pursuit of alternative theories of attention (See Watzl, 2017, for a sustained development of this thought).

A different objection to the present diagnosis of why psychological paradigms fail concerns levels of explanation. The paradigms are pitched at the sub-personal level, the thought goes, claiming to identify a sub-personal process or mechanism that constitutes one's attending. But the picture developed here of attention as an activity surely offers a personal-level explanation; it is agents who engage in the activity of attending. The suspicion might therefore arise that the two explanations may be perfectly compatible and indeed simultaneously correct: attention is an activity of the attending agent, but an accomplishment of the sub-personal attentional mechanism.

The personal/sub-personal distinction is a notoriously difficult one to draw, but it is nevertheless real. And however it should be drawn, it is no doubt true that theories operating on different sides of the distinction need not be regarded as direct rivals. However, they must be mutually compatible: the correct personal-level account of attending (or of any other phenomenon, for that matter) cannot exclude the correct sub-personal level account, and vice-versa. ${ }^{12}$ But such incongruence between the levels is precisely what we would face if we allow that attention may be a sub-personal accomplishment and a personal activity, given the contrasting logical features of each category. For example, if one's attending is interrupted, then on the personal level one has attended while on the sub-personal level one has not. Similarly, one could be attending on the personal level long after the sub-personal accomplishment has

\footnotetext{
12 Compare Mole (2011a: 22-3).
} 
been completed so that one is no longer (sub-personally) attending. And so on. The possibility of such bizarre mismatches undercuts the objection from different explanatory levels.

\section{References}

Allport, A. 1993. "Attention and Control: Have We Been Asking the Wrong Questions? A Critical Review of Twenty-five Years", in: Attention and Performance XIV: Synergies in Experimental Psycbology, Artificial Intelligence, and Cognitive Neuroscience, MIT Press: 183-218.

Allport, A. 1987. "Selection for Action", in H. Heuer and H. F. Sanders (eds.), Perspectives on Perception and Action. Erlbaum: 395-419.

Aune, B. 1967. Knowledge, Mind, and Nature, Random House.

Baddeley, A. D. 1966. "The Capacity for Generating Information by Randomization”, The Quarterly Journal of Experimental Psychology 18: 119-29.

Chisholm, R. M. 1957. Perceiving, Cornell University Press.

Chun, M. M., Golomb, J. D., and Turk-Browne, N. B. 2011. "A Taxonomy of External and Internal Attention". Annual Review of Psychology 62: 73-101.

Desimone R, Duncan J. 1995. "Neural Mechanisms of Selective Visual Attention”, Annual Review of Neuroscience 18:193-222.

Duncan, J. 2006. "Brain Mechanisms of Attention”. Quarterly Journal of Experimental Psychology 59: 2-27.

Galton, A. 2007. "Experience and History: Processes and their Relation to Events", Journal of Logic and Computation 18: 323-40.

Grice, P. 1961. "The Causal Theory of Perception”, Aristotelian Society Supplementary Volume 35: 121-52.

James, W. 1890. The Principles of Psychology, Henry Holt.

Kenny, A. 1963. Action, Emotion, and Will, Routledge and Kegan Paul.

Lavie N, Hirst A, de Fockert JW, Viding E. 2004. "Load Theory of Selective Attention and Cognitive Control”, Journal of Experimental Psychology 133: 339-54

Lavie, N., and Tsal, Y. 1994. "Perceptual Load as a Major Determinant of the Locus of Selection in Visual Attention", Perception \& Psychophysics 56: 183-197.

Lu, Z. L. \& Dosher, B. A. 2000. "Spatial Attention: Different Mechanisms for Central and Peripheral Temporal Precues?” Journal of Experimental Psychology 26: 1534-1548.

Mole, C. 2011a. Attention is Cognitive Unison. Oxford University Press

Mole, C. 2011b. “The Metaphysics of Attention”, in: C Mole, D. Smithies, and W. Wu (eds.), Attention: Philosophical and Psychological Essays, Oxford University Press: 60-77.

Mole, C. \& Zhao, J. 2016. "Vision and Abstraction: an Empirical Refutation of Nico Orlandi's Noncognitivism". Philosophical Psychology 29: 365-373. 
Mourelatos, A. 1978. "Events, Processes, and States", Linguistics and Philosophy 2: 415-34.

Parasuraman R. 1998. "The Attentive Brain: Issues and Prospects”, in The Attentive Brain, ed. R Parasuraman, MIT Press: 3-15.

Pashler H.E. 1998. The Psychology of Attention. Cambridge: MIT Press

Place, U. T. 1954. “The Concept of Heed”, British Journal of Psychology 45: 243-255.

Quinlan, P. T. 2003. "Visual Feature Integration Theory: Past, Present, and Future". Psychological Bulletin 129: 643-73.

Ryle, G. 1949. The Concept of Mind, Penguin Books.

Tootell R.B.H., Hadjikhani N., Hall E.K., Marrett S., Vanduffel W., et al. 1998. “The Retinotopy of Visual Spatial Attention". Neuron 21:1409-22

Treisman, A. 1998. “The Perception of Features and Objects', in: A. Baddeley and L. Weiskrantz (eds.), Attention: Selection, Awareness and Control, Oxford University Press: 5-35.

Treisman, A. and Gelade, G. 1980. “A Feature-Integration Theory of Attention”, Cognitive Psychology 12: $97-136$.

Vendler, Z. 1957. "Verbs and Times", Philosophical Review 66: 143-160.

Watzl, S. 2011. Review of “Attention Is Cognitive Unison” by Christopher Mole. Notre Dame Pbilosophical Reviews, https://ndpr.nd.edu/.

Watzl, S. 2017. Structuring Mind, Oxford University Press.

White, A. 1964. Attention, Blackwell.

Wu, W. 2014. Attention, Routledge.

Wu, W. 2011. “Attention as Selection for Action”. In C Mole, D. Smithies, and W. Wu (eds.), Attention: Philosophical and Psychological Essays, Oxford University Press: 97-116. 